\title{
Experimental Study on Dry Electrical Discharge Micro-Grinding of Tungsten Carbide
}

\author{
Y. J. Lu*, L. J. Li, J. Xie, C. L. Zhou, R. B. Guo and S. Y. Huo \\ School of Mechanical and Automotive Engineering, South China University of Technology, \\ Guangzhou 510640, China \\ *luyanjun_szu@163.com
}

Keywords: electrical discharge, diamond grinding wheel, micro-grinding, tungsten carbide.

\begin{abstract}
A novel dry electrical discharge micro-grinding (EDMG) method was proposed to grind tungsten carbide in this paper. The V-shape tip truing experimental setup was built to realize the precision truing of diamond grinding wheel micro tip. The trued V-tip diamond wheels after mechanical truing and dry ECD truing were employed to fabricate micro-groove structures on the surface of tungsten carbide. The machining qualities and topographies of V-groove machined by dry EDMG under different pulse discharge parameters were comparatively investigated. The experimental results indicated that the dry EDMG could effectively improve the machining quality of micro-structured surface against dry mechanical grinding. However, the worn of micro tip of diamond grinding wheel in dry EDMG was faster than the one in dry mechanical grinding. The appropriate pulse discharge parameters were duty cycle $d_{c}=10 \%$, open-circuit voltage $E=15 \mathrm{~V}$ and pulse frequency $f=5000 \mathrm{~Hz}$ in dry EDMG of tungsten carbide.
\end{abstract}

\section{Introduction}

The tungsten carbide material has been widely applied in cutting tool, molds and wear-resistant parts, etc. The regular micro-structures was manufactured on the surface of tungsten carbide, which may produce new engineering application [1]. However, as one of the hard and brittle material, the micro-structured surface machining of tungsten carbide is very difficult. It is known that a superabrasive diamond grinding wheel is an alternative to perform a grinding of tungsten carbide.

In order to improve the grinding efficiency and delay the worn of diamond wheel tip, the metal-bonded diamond grinding wheel was employed to grind tungsten carbide [2]. However, low efficiency of dressing and truing of metal-bonded diamond grinding wheel had been a bottleneck of industrialization. Therefore, the dry electro-contact discharge (ECD) dressing was developed along with ecological pollution-free to true micro-tip of diamond grinding wheel [3].

Traditionally, there was unmanageable pollution fluid in the grinding process of tungsten carbide. In recent years, more and more researchers have paid attention to dry cutting machining of tungsten carbide [4]. However, the ground surface quality of tungsten carbide using dry mechanical grinding has not been very well. Combine the advantages of high efficient electrical discharge machining (EDM) and high precise grinding machining [5], the dry electrical discharge micro-grinding (EDMG) machining method was developed to improve the machining efficiency and surface quality. Furthermore, the dry EDMG was an environmentally friendly grinding method without any cooling pollution fluid.

\section{Experimental setup of dry ECD and EDMG}

Fig. 1 shows the dry electro-contact discharge (ECD) truing of diamond grinding wheel V-tip. The pulse power supply was connected between copper electrode and conductive graphite brush. The pulse discharge was transmitted to diamond grinding wheel through graphite brush. The electric spark was produced when the grinding wheel approached to electrode. The rotary grinding wheel was driven to grind electrode along setting V-shape truing path. Gradually, the V-tip profile of grinding 
wheel was formed. The detail ECD truing conditions of SD1200 diamond grinding wheel V-tip were shown in Table 1.
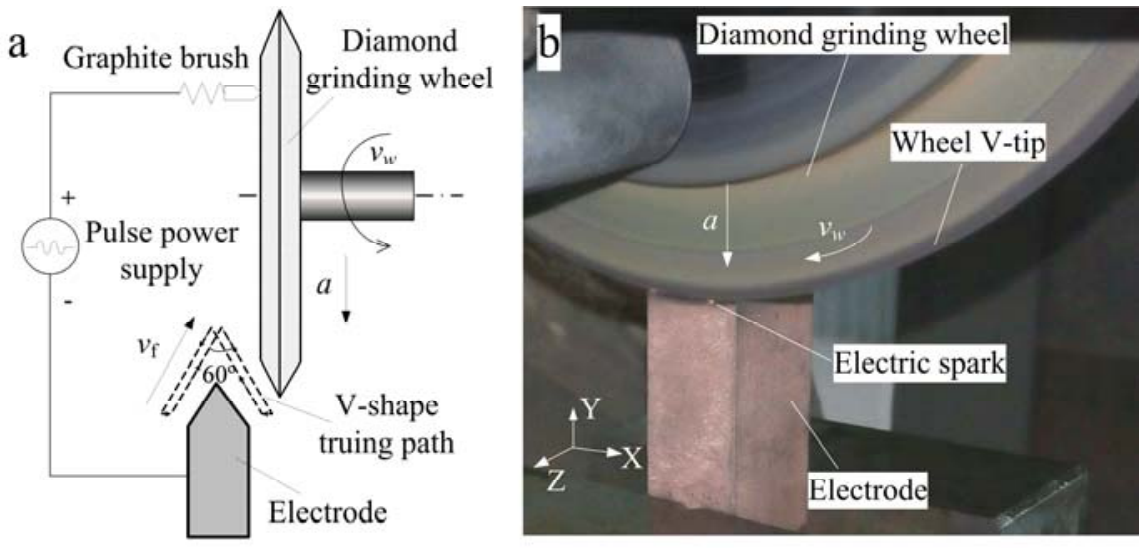

Fig. 1 Dry electro-contact discharge (ECD) truing of diamond grinding wheel V-tip: (a) schematic diagram of V-tip truing and (b) photo of ECD truing of wheel V-tip.

Table 1 The ECD truing conditions of SD1200 diamond grinding wheel V-tip

\begin{tabular}{cc}
\hline CNC grinder & SMART B818 \\
\hline $\begin{array}{c}\text { Diamond grinding } \\
\text { wheel }\end{array}$ & SD1200, metal bond, diameter $D=150 \mathrm{~mm}$, width $B=2.5 \mathrm{~mm}$ \\
\hline $\begin{array}{c}\text { Tool truing path } \\
\text { Truing electrode }\end{array}$ & Crossed V-shape interpolation path \\
Discharge & Pulse power supply, open-circuit voltage $E=25 \mathrm{~V}$, pulse frequency $f=5000 \mathrm{~Hz}$, \\
parameters & duty cycle $d_{c}=50 \%$ \\
Truing parameters & Wheel speed $v_{w}=18.8 \mathrm{~m} / \mathrm{s}$, feed speed $v_{\digamma}=200 \mathrm{~mm} / \mathrm{min}$, depth of cut $a=1 \mu \mathrm{mm}$ \\
Coolant & No \\
\hline
\end{tabular}

The trued diamond grinding wheel with V-tip was employed to fabricate micro-groove structures on the surface of conductive material using dry electrical discharge micro-grinding (EDMG) method. Fig. 2 shows the experimental setup of dry EDMG. In the experiment, the tungsten carbide was selected as workpiece. The pulse power supply was connected between diamond grinding wheel and tungsten carbide. The V-groove machining path was shown in Fig. 2a. When trued V-tip diamond wheel cut tungsten carbide, the electric spark was produced between chip and metal bond from diamond grinding wheel (see Fig. 2b). The machined V-groove depth and space was $200 \mu \mathrm{m}$ and 400 $\mu \mathrm{m}$, respectively.
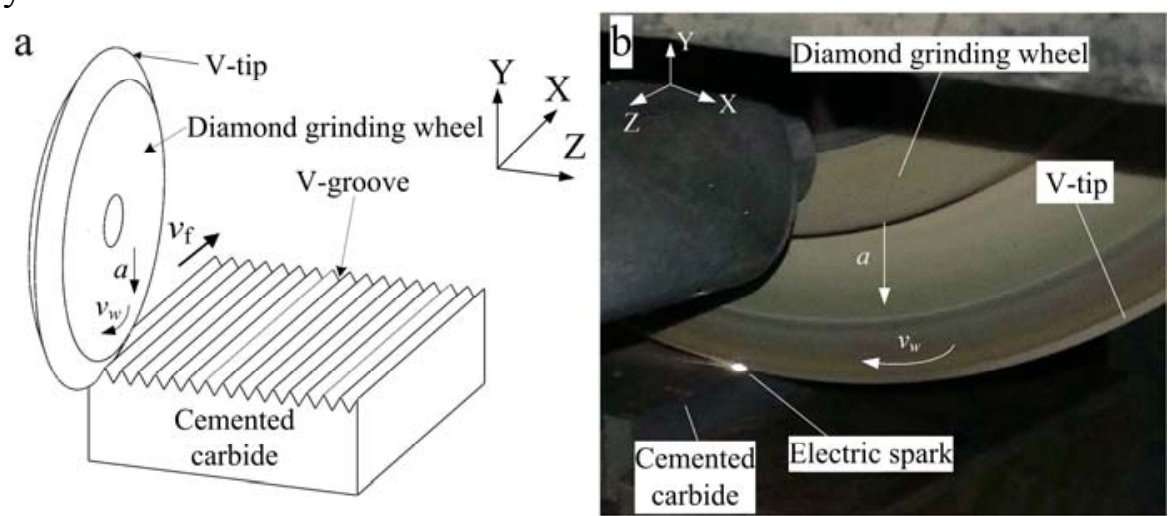

Fig. 2 Dry electrical discharge micro-grinding (EDMG) of tungsten carbide: (a) schematic diagram of $\mathrm{V}$-groove grinding and (b) photo of dry EDMG of tungsten carbide.

The detail dry EDMG conditions of trued SD1200 V-tip diamond grinding wheel were shown in Table 2. The processing effects of dry EDMG for tungsten carbide under different pulse discharge parameters were observed. In order to investigate the effect of mechanical truing and dry ECD truing on micro-grinding machining of diamond grinding wheel, the $\mathrm{V}$-tip wheels after mechanical truing and dry ECD truing were used to grind V-groove on the surface of tungsten carbide without any 
coolant. The mechanical truing parameters were wheel speed $v_{w}=18.8 \mathrm{~m} / \mathrm{s}$, feed speed $v_{\digamma}=800$ $\mathrm{mm} / \mathrm{min}$ and depth of cut $a=20 \mu \mathrm{m}$. The mechanical truer was green silicon carbide oilstones (\#80 and \#600).

Table 2 Conditions of dry EDMG

\begin{tabular}{|c|c|c|}
\hline CNC grinder & \multicolumn{2}{|c|}{ SMART B818 } \\
\hline $\begin{array}{l}\text { Diamond } \\
\text { grinding wheel }\end{array}$ & \multicolumn{2}{|c|}{ SD1200, metal bond, diameter $D=150 \mathrm{~mm}$, width $B=2.5 \mathrm{~mm}$} \\
\hline Workpiece & \multicolumn{2}{|c|}{ Tungsten carbide } \\
\hline $\begin{array}{l}\text { Grinding } \\
\text { parameters }\end{array}$ & \multicolumn{2}{|c|}{$\begin{array}{l}\text { Wheel speed } v_{w}=18.8 \mathrm{~m} / \mathrm{s} \text {, feed speed } v_{\digamma}=200 \mathrm{~mm} / \mathrm{min} \text {, rough machining: depth of } \\
\text { cut } a=5 \mu \mathrm{m} \text {, finish machining: depth of cut } a=1 \mu \mathrm{m}\end{array}$} \\
\hline Coolant & \multicolumn{2}{|c|}{ No } \\
\hline \multirow{9}{*}{$\begin{array}{l}\text { Pulse discharge } \\
\text { parameters }\end{array}$} & 1 & $\begin{array}{c}E=25 \mathrm{~V}, f=5000 \mathrm{~Hz} \\
d_{c}=10 \%, \sum a=150 \mu \mathrm{m}\end{array}$ \\
\hline & 2 & $\begin{array}{c}E=15 \mathrm{~V}, f=5000 \mathrm{~Hz} \\
d_{c}=10 \%, \sum a=150 \mu \mathrm{m}\end{array}$ \\
\hline & 3 & $\begin{array}{c}E=5 \mathrm{~V}, f=5000 \mathrm{~Hz} \\
d_{c}=10 \%, \sum a=150 \mu \mathrm{m}\end{array}$ \\
\hline & 4 & $\begin{aligned} E & =15 \mathrm{~V}, f=5000 \mathrm{~Hz} \\
d_{c} & =30 \%, \sum a=150 \mu \mathrm{m}\end{aligned}$ \\
\hline & 5 & $\begin{array}{c}E=15 \mathrm{~V}, f=5000 \mathrm{~Hz} \\
d_{c}=50 \%, \sum a=150 \mu \mathrm{m}\end{array}$ \\
\hline & 6 & $\begin{aligned} E & =15 \mathrm{~V}, f=3000 \mathrm{~Hz} \\
d_{c} & =10 \%, \sum a=150 \mu \mathrm{m}\end{aligned}$ \\
\hline & 7 & $\begin{aligned} E & =15 \mathrm{~V}, f=1000 \mathrm{~Hz} \\
d_{c} & =10 \%, \sum a=150 \mu \mathrm{m}\end{aligned}$ \\
\hline & 8 & $\begin{array}{c}E=15 \mathrm{~V}, f=5000 \mathrm{~Hz} \\
d_{c}=10 \%, \sum a=200 \mu \mathrm{m}\end{array}$ \\
\hline & 9 & $\begin{array}{c}E=15 \mathrm{~V}, f=5000 \mathrm{~Hz} \\
d_{c}=10 \%, \sum a=250 \mu \mathrm{m}\end{array}$ \\
\hline
\end{tabular}

\section{Results and discussions}

Fig. 3 shows the machined V-groove topographies of tungsten carbide surface using trued V-tip diamond grinding wheels by mechanical micro-grinding and dry EDMG methods. Compared with the V-groove array structures from Fig. 3a and Fig. 3b, it is obviously seen that, after machining using mechanical trued V-tip wheel, the form accuracy of V-groove was higher and tip radius of V-groove was less. Moreover, the V-groove array structures were also quite regular. However, much metal burr and fragment chip on the tip and edge of $\mathrm{V}$-groove were produced, leading to poor surface quality. Higher form accuracy of V-tip can be obtained using mechanical truing against ECD truing. Therefore, the V-groove array structures with higher form accuracy can be machined using diamond wheel with V-tip after mechanical truing. The surface quality was better using ECD trued V-tip wheel. The reason is that the grain protrusion height of wheel surface was higher using ECD dressing and truing against mechanical truing. Compared with the V-groove array structures from Fig. $3 \mathrm{~b}$ and Fig. $3 \mathrm{c}$, it is found that the form accuracy of $\mathrm{V}$-groove was worse through dry EDMG against dry grinding. This is because the diamond wheel tip was easier to wear in dry electrical discharge grinding. However, the tip and edge of V-groove were much smoother after dry EDMG. This indicates that micro electrical spark discharge is beneficial to reduce the friction and scratch among workpiece and chip. Besides, the electrical spark discharge may play an important role in self-sharpness for diamond grinding wheel. Therefore, dry EDMG can improve surface quality of workpiece.

Fig. 4 shows the machined V-groove topographies of tungsten carbide surface using trued SD1200 V-tip diamond grinding wheel by dry EDMG under different open-circuit voltages $E$. The electrical 
discharge conditions were pulse frequency $f=5000 \mathrm{~Hz}$, duty cycle $d_{c}=50 \%$ and cumulative depth of cut $\sum a=150 \mu \mathrm{m}$. As seen from Fig. 4, tip radius of $\mathrm{V}$-groove gradually increased with the increase of open-circuit voltage. The reason is that high open-circuit voltage produced large pulse discharge energy and heat, which removed too much metal bond, leading to worse worn of wheel tip. Therefore, the open-circuit voltage $E$ should be controlled under $15 \mathrm{~V}$ in the process of dry EDMG of tungsten carbide using trued SD1200 V-tip diamond grinding wheel.

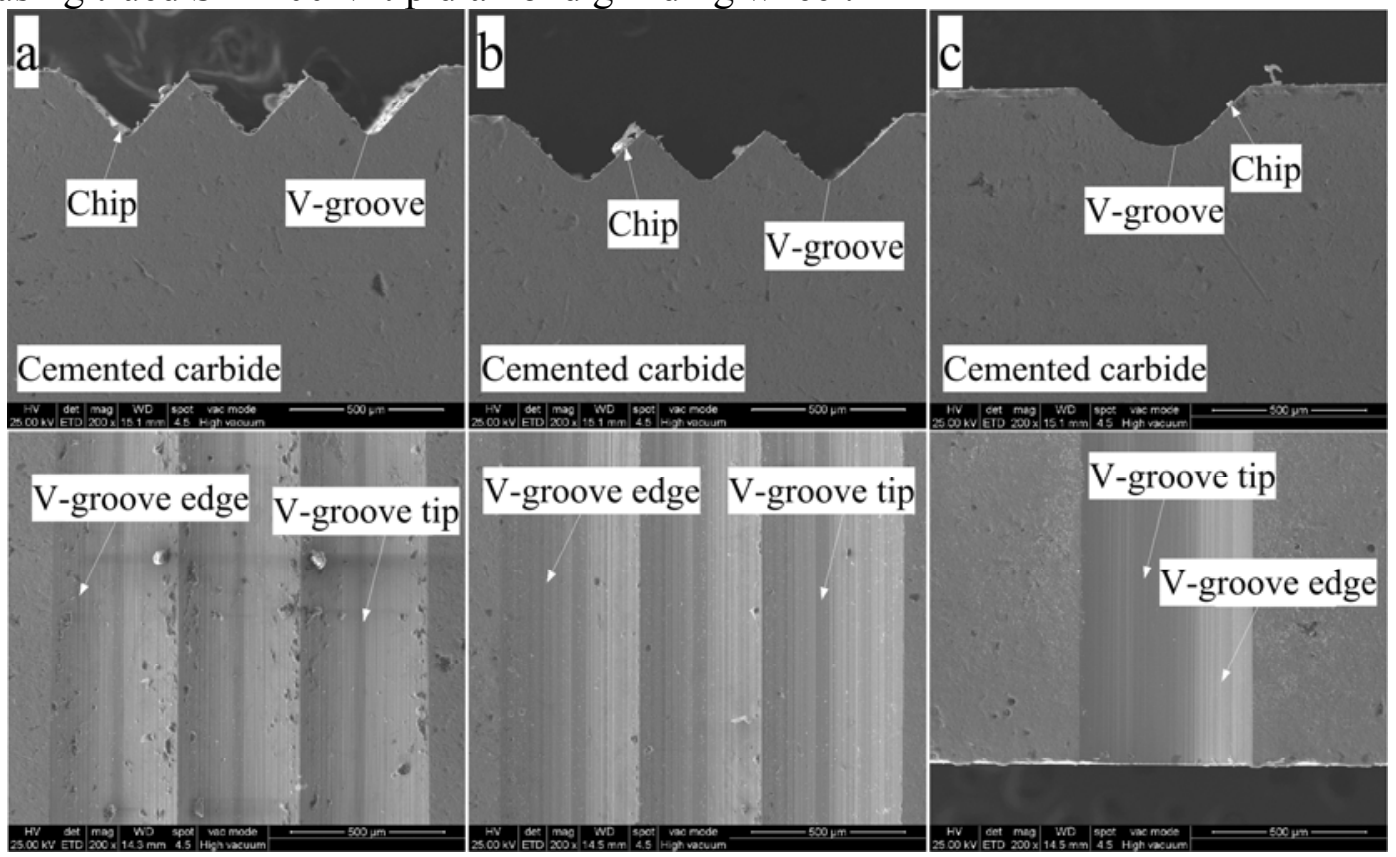

Fig. 3 V-groove topographies of tungsten carbide surface using trued SD1200 V-tip diamond grinding wheels by mechanical micro-grinding and dry EDMG: (a) dry micro-grinding after mechanical truing, (b) dry micro-grinding after ECD truing and (c) dry EDMG after ECD truing.
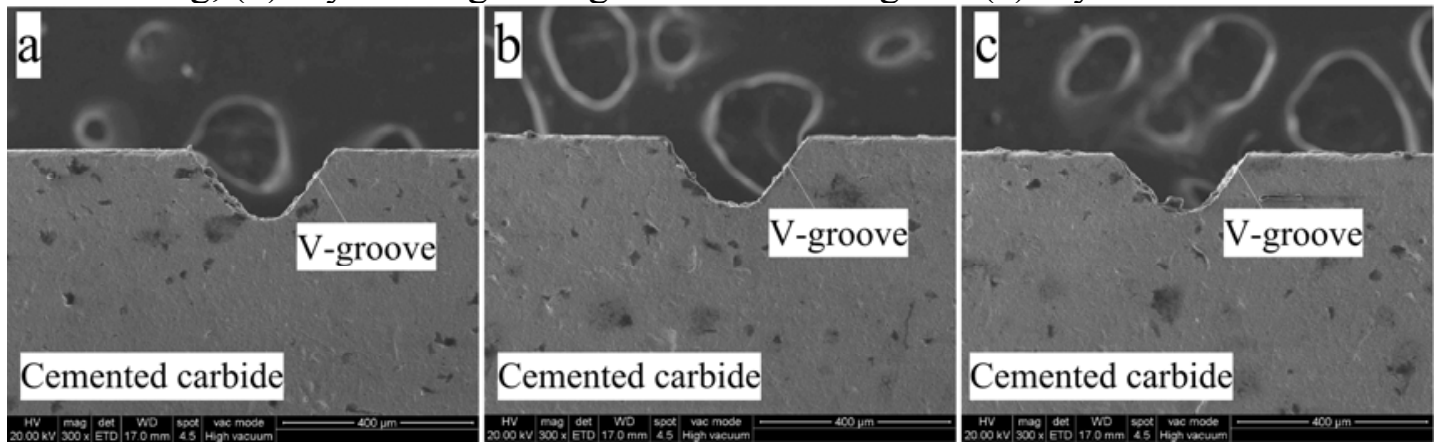

Fig. $4 \mathrm{~V}$-groove topographies of tungsten carbide surface using trued SD1200 V-tip diamond grinding wheel by dry EDMG under different open-circuit voltages $E$ : (a) $E=15 \mathrm{~V}$, (b) $E=20 \mathrm{~V}$ and (c) $E=25 \mathrm{~V}$.

Fig. 5 shows the machined V-groove topographies of tungsten carbide surface using trued SD1200 $\mathrm{V}$-tip diamond grinding wheel by dry EDMG under different duty cycles $d_{c}$. The electrical discharge conditions were pulse frequency $f=5000 \mathrm{~Hz}$, open-circuit voltage $E=15 \mathrm{~V}$ and cumulative depth of cut $\sum a=150 \mu \mathrm{m}$. It is shown that the tip and edge of $\mathrm{V}$-groove became much rougher with the increase of duty cycle. This is because high duty cycle and long pulse discharge time produced arc discharge, leading to inadequate removal of spark discharge between wheel and chip. When the duty cycle $d_{c}=10 \%$, tip radius of $\mathrm{V}$-groove reached least and discharge melted chips near the edge of V-groove were also least. Hence, the adequate duty cycle $d_{c}$ was $10 \%$ in the process of dry EDMG of tungsten carbide using trued SD1200 V-tip diamond grinding wheel.

Fig. 6 shows the machined V-groove topographies of tungsten carbide surface using trued SD1200 V-tip diamond grinding wheel by dry EDMG under different pulse frequencies $f$. The electrical discharge conditions were duty cycle $d_{c}=10 \%$, open-circuit voltage $E=15 \mathrm{~V}$ and cumulative depth of cut $\sum a=150 \mu \mathrm{m}$. It is seen that the tip and edge of V-groove became much smoother with the increase 
of pulse frequency. The reason is that large pulse frequency and short pulse discharge time easily produced micro spark discharge removal so that chip was timely removed. When the pulse frequency $f=5000 \mathrm{~Hz}$, tip radius of $\mathrm{V}$-groove was least and discharge melted chips near the edge of $\mathrm{V}$-groove were also least. As a result, the suitable pulse frequency $f$ was $5000 \mathrm{~Hz}$ in the process of dry EDMG of tungsten carbide using trued SD1200 V-tip diamond grinding wheel.

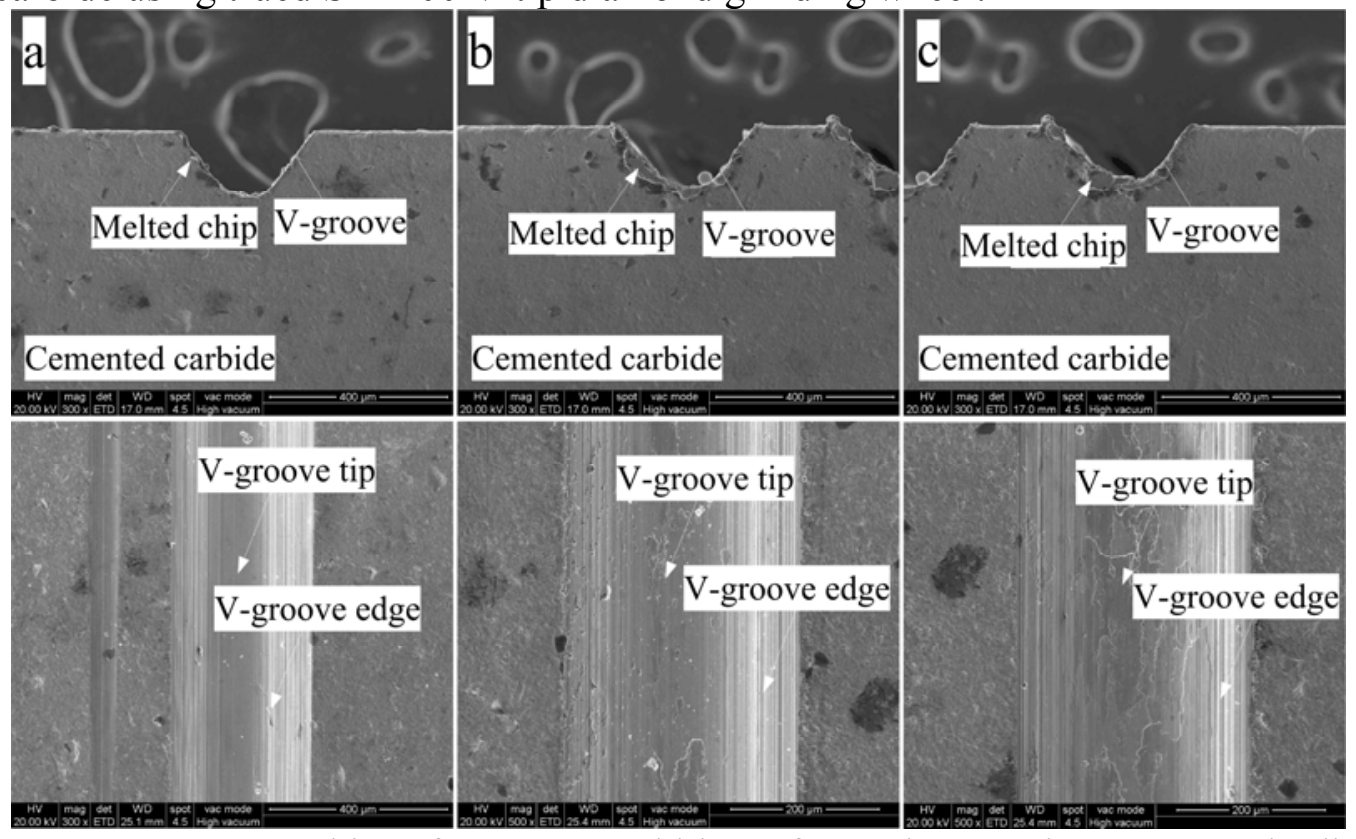

Fig. 5 V-groove topographies of tungsten carbide surface using trued SD1200 V-tip diamond grinding wheel by dry EDMG under different duty cycles $d_{c}$ : (a) $d_{c}=10 \%$, (b) $d_{c}=30 \%$ and (c)
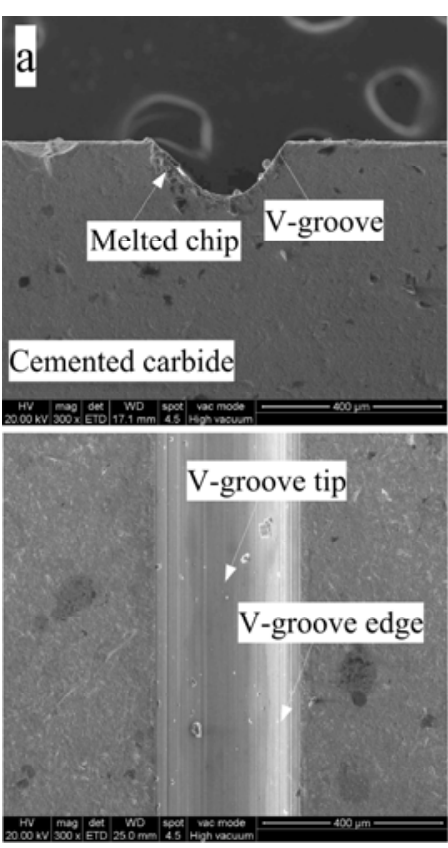

$d_{c}=50 \%$
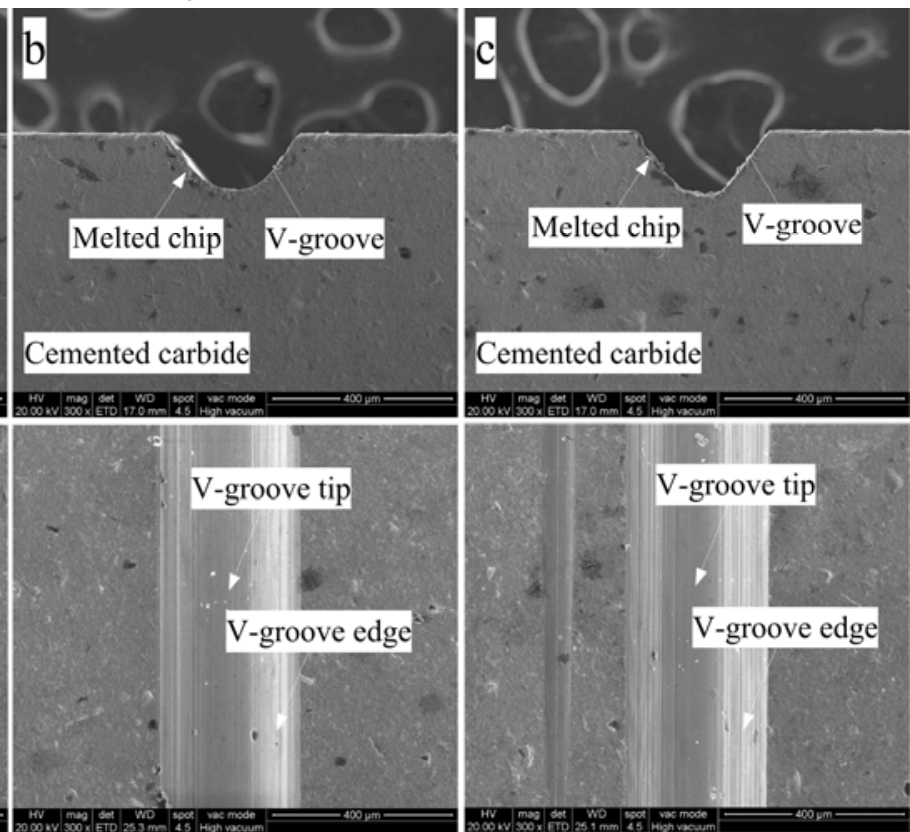

Fig. $6 \mathrm{~V}$-groove topographies of tungsten carbide using trued SD1200 V-tip diamond grinding wheel by dry EDMG under different pulse frequencies $f$ : (a) $f=1000 \mathrm{~Hz}$, (b) $f=3000 \mathrm{~Hz}$ and (c) $f=5000 \mathrm{~Hz}$.

Fig. 7 shows the machined V-groove topographies of tungsten carbide surface using trued SD1200 V-tip diamond grinding wheel by dry EDMG under cumulative depths of cut $\sum a$. It is seen that the tip radius increased and $\mathrm{V}$-groove tip and edge became much rougher with the increase of cumulative depth of cut. This is because the larger cumulative depth of cut was, the more micro worn of wheel tip was. 

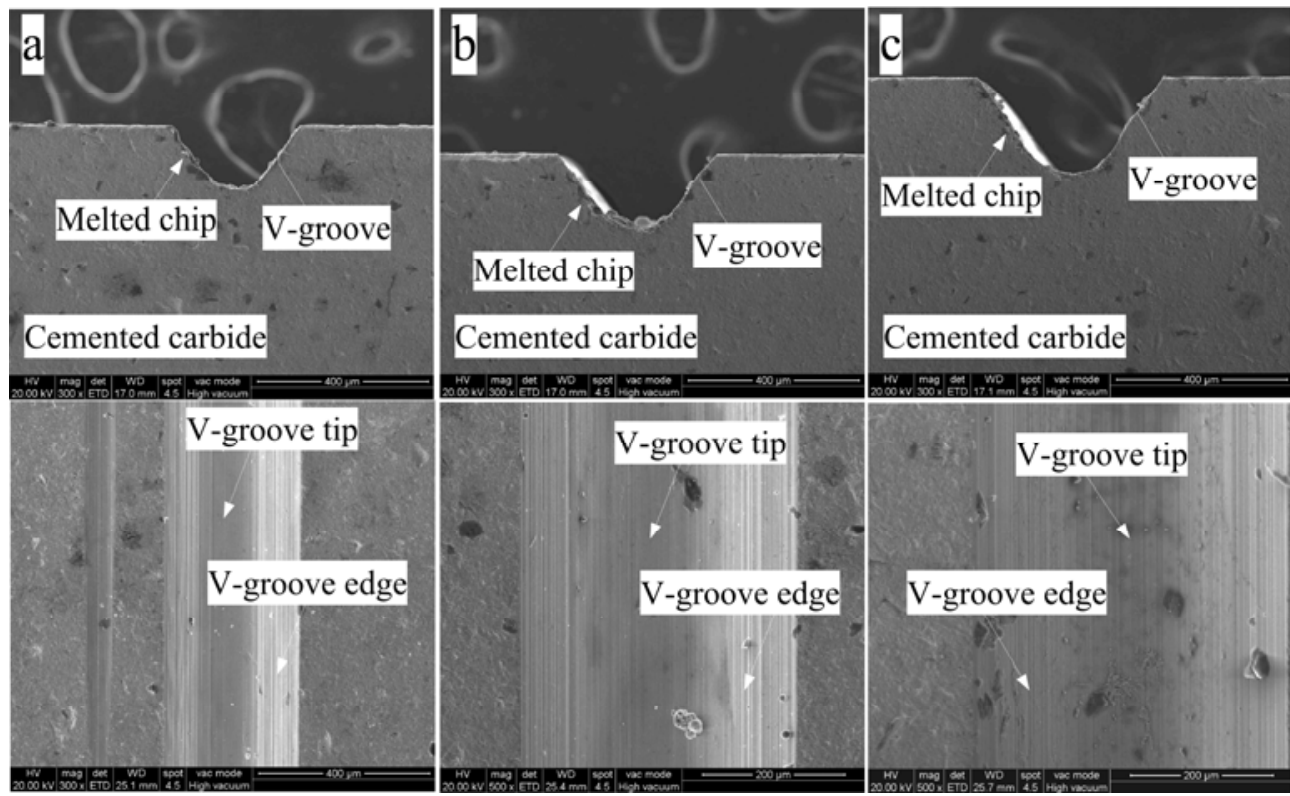

Fig. 7 V-groove topographies of tungsten carbide using trued SD1200 V-tip diamond wheel by dry EDMG under different cumulative depths of cut $\sum a$ : (a) $\sum a=150 \mu \mathrm{m}$, (b) $\sum a=200 \mu \mathrm{m}$ and (c) $\sum a=250$ $\mu \mathrm{m}$.

\section{Summary}

The dry electrical discharge micro-grinding (EDMG) processing technology was developed in this paper. Compared with dry mechanical grinding, the dry EDMG could effectively improve the machining quality of micro-structured surface. However, the worn of micro tip of diamond grinding wheel in dry EDMG was faster than the one in dry mechanical grinding. In the dry EDMG of tungsten carbide. The appropriate pulse discharge parameters were duty cycle $d_{c}=10 \%$, open-circuit voltage $E=15 \mathrm{~V}$ and pulse frequency $f=5000 \mathrm{~Hz}$.

\section{Acknowledgements}

This project was supported by the China Postdoctoral Science Foundation [Grant No. 2016M602460], the Opening Project of the National Engineering Search Center of Near-net-shape Forming for Metallic Materials [Grant No. 2015001], the Fundamental Research Funds for the Central Universities [Grant No. 2015ZM105], the Science and Technology Planning Project of Guangdong Province [Grant No. 2016A040403043] and the Youth Projects for Creative Talents of Educational Commission of Guangdong Province [Grant No. 2015KQNCX009].

\section{References}

[1] K. Egashira, S. Hosono, S. Takemoto, Y. Masao, Fabrication and cutting performance of cemented tungsten carbide micro-cutting tools, Precis. Eng. 35 (2011) 547-553.

[2] Q. L. Zhao, B. Guo, Ultraprecision Grinding Technology of Microstructured Optical Functional Molds, J. Mech. Eng. 47 (2011) 177-185.

[3] J. Xie, H. F. Xie, M. J. Luo, T. W. Tan, P. Li, Dry electro-contact discharge mutual-wear truing of micro diamond wheel V-tip for precision micro-grinding, Int. J. Mach. Tools Manuf. 60 (2012) 44-51.

[4] S.Y. Luo, Y.C. Liu, C.C. Chou, T.C. Chen, Performance of powder filled resin-bonded diamond wheels in the vertical dry grinding of tungsten carbide, J. Mater. Process. Technol. 118 (2001) 329-336.

[5] Z. B. Yu, T. Jun, K. Masanori, Dry electrical discharge machining of cemented carbide, J. Mater. Process. Technol. 149 (2004) 353-357. 